\title{
PENGARUH LINGKUNGAN KERJA PERAWAT TERHADAP PELAKSANAAN PRAKTEK KEPERAWATAN DI RUMAH SAKIT UMUM Dr. SAIFUL ANWAR MALANG TAHUN 2006
}

\section{THE INFLUENCE OF NURSES' WORKING ENVIRONMENT TO IMPLEMENTATION NURSING PRACTICE IN GENERAL HOSPITAL Dr. SAIFUL ANWAR MALANG YEAR 2006}

\author{
Kuswantoro Rusca Putra*, Achir Yani S. Hamid ${ }^{* *}$, Mustikasari** \\ * Program Studi IImu Keperawatan Fakultas Kedokteran Universitas Brawijaya Malang \\ ${ }^{* *}$ Fakultas Keperawatan Universitas Indonesia Jakarta
}

\begin{abstract}
The implementation of nursing practice is related to nurses' working environment. The working environment components consist of leadership, culture and management; control over workload; control over practice; and adequate source. The purpose of this study is to identify any correlation between the nurses work environment with the implementation of nursing practice. The research was conducted in IRNA (Inpatients Ward) I and of IRNA II RSU Dr. Saiful Anwar on May $1^{\text {st }}$ until 20th, 2006. Correlation was chosen as the research design using cross sectional study on 196 nurses with two instruments: nurses' work environment, and implementation of nursing practice. The result based on analysis with regression linier indicates that there is a significant correlation between working nurse environment (leadership, culture and management; control over workload; control over practice; and adequate source) with the implementation of nursing practice $(p<0.05)$ and control over practice is the biggest sub variable that influences the implementation of nursing practice( $B=1.302)$. In conclusion, the nurse's working environment influences implementation of nursing practice in hospital.
\end{abstract}

Keywords: Work environment, Implementation of nursing practice

\section{PENDAHULUAN}

Era globalisasi merupakan tantangan, masalah, dan sekaligus potensi untuk pengembangan pelayanan kesehatan yang berkualitas. Peran perawat dalam menghadapi era globalisasi adalah dengan memberikan pelayanan perawatan secara profesional, yaitu perawat secara aktif terlibat dalam pembuatan keputusan terkait dengan permasalahan yang dihadapi klien dan memiliki kebebasan untuk melakukan praktek serta melakukan hubungan kolaborasi dengan dokter secara baik. Manfaat pelaksanaan praktek keperawatan secara profesional pada rumah sakit adalah terjadinya peningkatan kepuasan kerja perawat, terciptanya lingkungan kerja yang aman, menurunnya ketegangan emosi perawat dalam melakukan pekerjaannya, menurunnya angka cedera karena jarum suntik yang dialami perawat, serta penurunan angka kematian klien yang di rawat (1).

Fenomena yang terjadi terkait dengan pelaksanaan praktek keperawatan di banyak negara masih sering ditemukan perawat menghabiskan waktunya untuk melakukan pekerjaan di luar keperawatan yang bukan menjadi tanggung jawabnya dan tentunya kondisi ini akan berdampak pada tidak tersedianya waktu yang cukup untuk melakukan

Jurnal Kedokteran Brawijaya, Vol. XXIII, No. 1, April 2007 Korespondensi Kuswantoro RP; Program Studi IImu Keperawatan FK Unibraw; Jl. Veteran Malang 65145; Telp. 0341-575857 praktek keperawatan secara berkesinambungan dan komprehensif bagi klien maupun keluarganya (2). Fenomena pelaksanaan praktek keperawatan seperti ini juga masih sering ditemukan pada beberapa rumah sakit di Indonesia. $(3,4)$. Kemungkinan fenomena ini terjadi diakibatkan karena masalah lingkungan kerja perawat yang belum diselesaikan dengan baik (5).

Salah satu syarat untuk dapat menunjang pelaksanaan praktek keperawatan secara profesional adalah dengan memperhatikan lingkungan kerja perawat (6). Lingkungan kerja yang berkualitas tinggi sangat bermanfaat bagi perawat dan dapat meningkatkan kualitas perawatan klien $(7,8)$. Komponen dari lingkungan kerja perawat ini antara lain meliputi komponen kepemimpinan, dan budaya; kendali terhadap praktek; kendali terhadap beban kerja; dan sumbersumber yang adekuat bagi terlaksananya pelayanan keperawatan yang berkualitas (7).

Kondisi lingkungan kerja dan pelaksanaan praktek keperawatan profesional di Indonesia belum banyak diketahui. Berdasarkan hal di atas, maka dirasakan perlu untuk melakukan penelitian tentang hubungan lingkungan kerja perawat dengan pelaksanaan praktek keperawatan di Rumah Sakit Umum (RSU) Dr. Saiful Anwar Malang.

Penelitian ini bertujuan untuk mengidentifikasi pengaruh lingkungan kerja perawat (kepemimpinan, manajemen, dan budaya; kendali terhadap beban kerja; 
kendali terhadap praktek; dan sumber yang memadai) terhadap pelaksanaan praktek keperawatan.

\section{METODE}

Jenis penelitian ini adalah deskriptif korelasional dengan desain cross sectional, data variabel independen, confounding dengan variabel dependen diambil pada saat bersamaan. Penelitian ini dilakukan di RSU Dr. Saiful Anwar Malang, khususnya instalasi rawat inap (IRNA) I dan II mulai tanggal 1 Mei sampai dengan 20 Mei 2006.

Sampel yang menjadi responden dalam penelitian ini adalah total populasi perawat yang bekerja di IRNA I dan II dengan kriteria inklusi perawat yang bekerja di ruang rawat inap RSU Dr. Saiful Anwar Malang, tidak sedang cuti, tidak sedang menjalankan Program orientasi kurang dari 6 bulan, tugas belajar, atau on the job training, dan bersedia menandatangani informed consent dengan jumlah sampel 196 perawat. Instrumen penelitian menggunakan kuesioner yang dipersepsikan oleh perawat terbagi dalam dua bagian, yaitu (1) lingkungan kerja perawat yang meliputi dari kepemimpinan, manajemen, dan budaya, yaitu persepsi responden tentang rentang kendali, kepemimpinan/ manajemen, dukungan dan komunikasi, penghargaan dan penghormatan serta pelibatan perawat dalam pengambilan keputusan; kendali terhadap beban kerja, yaitu persepsi responden tentang kendali terhadap beban kerja yang dialami di rumah sakit meliputi adanya kesesuaian antara tingkat ketergantungan pasien dengan asuhan yang akan diberikan, tersedianya waktu yang cukup untuk melakukan praktek secara profesional, kompetensi,kesesuaian perbandingan antara pasien dengan perawat serta fleksibelitas dalam pengaturan jadwal dinas; kendali terhadap praktek, yaitu persepsi responden tentang kendali terhadap praktek meliputi adanya otonomi bagi perawat untuk melakukan praktek keperawatan secara profesional, adanya kejelasan kompetensi bagi perawat untuk melakukan pekerjaannya serta adanya hubungan kolaborasi antara dokter dengan perawat; dan sumber yang memadai, yaitu persepsi responden tentang sumber yang memadai dalam praktek keperawatan meliputi kesempatan pengembangan profesional, persediaan, dan perlengkapan; dan (2) pelaksanaan praktek keperawatan yang meliputi pengkajian, diagnosa keperawatan, perencanaan, pelaksanaan, dan evaluasi.
Instrumen untuk mengukur lingkungan kerja perawat diadopsi dari instrumen lingkungan kerja yang dibuat oleh Pengurus Pusat Persatuan Perawat Nasional Indonesia (PP-PPNI) sebanyak 74 item pertanyaan kemudian dikembangkan oleh peneliti menjadi 68 item pertanyaan. Sedangkan instrumen pelaksanaan praktek keperawatan diadopsi dari standar praktek keperawatan profesional yang disusun PP-PPNI kemudian peneliti kembangkan menjadi pertanyaan sebanyak 55 item pertanyaan. Masing-masing pertanyaan diberi skor 4 sampai 1 (selalu sampai tidak pernah). Hasil uji instrumen menunjukkan bahwa instrumen lingkungan kerja perawat cukup valid dan reliabel pada $r>0.349$ dan $\propto=0.97$. Sedangkan instrumen pelaksanaan praktek keperawatan cukup valid dan reliabel pada $r>$ 0.349 dan $\propto=0.96$. Pertanyaan yang kurang valid dan kurang reliabel telah dilakukan perbaikan untuk meminimalkan kesalahan pengukuran.

Total skor variabel lingkungan kerja perawat beserta sub variabelnya yaitu kepemimpinan, manajemen, dan budaya; kendali terhadap beban kerja; kendali terhadap praktek dan sumber yang memadai serta variabel pelaksanaan praktek keperawatan ditampilkan dalam bentuk mean, median, standar deviasi, dan $\mathrm{Cl} 95 \%$ sedangkan analisis data yang digunakan untuk mengetahui pengaruh lingkungan kerja perawat terhadap pelaksanaan praktek keperawatan adalah menggunakan regresi linier ganda.

\section{HASIL PENELITIAN}

Data yang dikaji dalam penelitian ini adalah meliputi lingkungan kerja perawat (kepemimpinan, manajemen, dan budaya; kendali terhadap beban kerja; kendali terhadap praktek; dan sumber yang memadai) dan pelaksanaan praktek keperawatan yang akan dijelaskan dalam Tabel 1.

Berdasarkan Tabel 1 dapat diprediksi dengan menggunakan tingkat kepercayaan $95 \%$ skor lingkungan kerja perawat yang dipersepsikan oleh perawat meliputi kepemimpinan, manajemen, dan budaya skornya berkisar antara 47,02 - 48,42; Kendali Terhadap Beban Kerja skornya berkisar antara 30,89- 31,95; Kendali Terhadap Praktek skornya berkisar antara 100,77-103,40; dan Sumber yang Memadai skornya berkisar antara 32,55- 33,93. Sedangkan pelaksanaan praktek keperawatan skornya berkisar antara 168,69 - 174,31.

Tabel 1. Distribusi Statistik Lingkungan Kerja Perawat dan Pelaksanaan Praktek Keperawatan di IRNA I dan IRNA II RSU Dr. Saiful Anwar Malang Bulan Mei 2006 ( $n=196)$

\begin{tabular}{lccccc}
\hline \multicolumn{1}{c}{ Variabel } & Mean & Median & SD & Min-Mak & 95\% Cl \\
\hline Lingkungan Kerja Perawat (Total) & 214,46 & 215,00 & 16,669 & $173-267$ & $212,12-216,81$ \\
Kepemimpinan, Manajemen dan Budaya & 47,72 & 47,50 & 4,953 & $35-66$ & $47,02-48,42$ \\
Kendali Terhadap Beban Kerja & 31,42 & 32,00 & 3,752 & $21-40$ & $30,89-31,95$ \\
Kendali Terhadap Praktek & 102,09 & 102,00 & 9,320 & $83-142$ & $100,77-103,40$ \\
Sumber yang Memadai & 33,24 & 33,00 & 4,929 & $22-45$ & $32,55-33,93$ \\
Pelaksanaan Praktek Keperawatan & 171,50 & 174,00 & 19,973 & $108-209$ & $168,69-174,31$ \\
\hline
\end{tabular}


Tabel 2. Hasil Analisis Bivariat Lingkungan Kerja Perawat dengan Pelaksanaan Praktek Keperawatandi IRNA I dan IRNA II RSU Dr. Saiful Anwar Malang, Bulan Mei 2006 (n=196)

\begin{tabular}{lcc}
\hline \multirow{2}{*}{ Variabel Independen } & \multicolumn{2}{c}{ Variabel Dependen (Pelaksanaan Praktek Keperawatan) } \\
\cline { 2 - 3 } & Korelasi $(\mathbf{r})$ & $\boldsymbol{p}$ Value \\
\hline Lingkungan Kerja Perawat (Total) & 0,479 & 0,000 \\
Kepemimpinan, Manajemen, dan Budaya & 0,209 & 0,003 \\
Kendali Terhadap Beban Kerja & 0,141 & 0,049 \\
Kendali Terhadap Praktek & 0,580 & 0,000 \\
Sumber Yang Memadai & 0,207 & 0,004 \\
\hline
\end{tabular}

Korelasi antara variabel lingkungan kerja perawata (Kepemimpinan, manajemen, dan budaya, kendali terhadap beban kerja, kendali terhadap praktek, dan sumber yang memadai) dengan pelaksanaan praktek keperawatan dapat dilihat pada Tabel 2

Berdasarkan Tabel 2 di atas diketahui bahwa lingkungan kerja perawat dan semua subvaribelnya memiliki hubungan dengan pelaksanaan praktek keperawatan $(p<$ 0,05). Tingkat keeratan hubungan antara lingkungan kerja perawat dan Kendali Terhadap Praktek dengan pelaksanaan praktek keperawatan adalah sedang. Keeratan hubungan antara Kepemimpinan, Manajemen, dan Budaya serta sumber yang memadai dengan pelaksanaan praktek keperawatan adalah rendah. Keeratan hubungan antara Kendali Terhadap Beban Kerja dengan pelaksanaan praktek keperawatan adalah lemah. Pola hubungan dalam penelitian ini bersifat positif artinya semakin baik lingkungan kerja perawat akan semakin baik pelaksanaan praktek keperawatannya.

Pada analisis regresi linier ganda didapatkan bahwa $35,9 \%$ dari subvariabel kendali terhadap beban kerja, kendali terhadap praktek dan sumber-sumber yang memadai yang menjadi penentu pelaksanaan praktek keperawatan. Subvariabel yang paling signifikan dan paling besar perannya sebagai penentu pelaksanaan praktek keperawatan adalah kendali terhadap praktek dengan $p=0,000$ dan koefisien betha $=1,301$ artinya pelaksanaan praktek keperawatan akan bertambah 1,301 bila perawat memiliki kendali terhadap praktek setelah dikontrol subvariabel kendali terhadap beban kerja dan sumber yang memadai.

\section{DISKUSI}

\section{Pengaruh Lingkungan Kerja Perawat Terhadap Pelaksanaan Praktek Keperawatan}

Pelaksanaan praktek keperawatan akan dilakukan secara profesional apabila didukung dengan lingkungan kerja perawat yang profesional pula $(6,7,9)$. Hal ini sesuai dengan temuan dalam penelitian ini yang menunjukkan ada pengaruh antara lingkungan kerja perawat dengan pelaksanaan praktek keperawatan. Kondisi lingkungan kerja yang baik dapat meningkatkan kualitas hidup dalam bekerja yang berdampak pada produktivitas kerja tenaga kesehatan profesional yang baik pula(10). Upaya yang dapat dilakukan untuk mengelola lingkungan kerja perawat secara optimal adalah melalui pemberdayaan perawat untuk lebih memahami dan mengaplikasikan kemampuanya dalam membuat keputusan terkait prakteknya disesuaikan dengan otoritas yang dimilikinya secara bertanggung jawab akan berdampak terhadap terwujudnya pelaksanaan praktek keperawatan secara profesional.

Pengaruh Kepemimpinan, Manajemen dan Budaya Terhadap Pelaksanaan Praktek Keperawatan

Kemampuan yang dimiliki oleh manajer dalam mengelola manajemen pelayanan, adanya pelaksanaan supervisi klinik yang dilakukan oleh pemimpin, adanya dukungan dari pemimpin dan pemberian kesempatan perawat untuk melakukan aktivitas refleksi terhadap pekerjaannya serta adanya budaya organisasi yang berlaku dalam suatu rumah sakit akan mempengaruhi kualitas kondisi lingkungan kerja perawat yang berdampak pada kualitas pemberian asuhan keperawatan yang dilakukan oleh perawat pada klien $(8,10,11)$. Hal ini sesuai dengan temuan pada penelitian ini yang menunjukkan adanya pengaruh yang signifikan antara kepemimpinan, manajemen dan budaya dengan pelaksanaan praktek keperawatan dengan pola hubungan yang positif, artinya semakin baik kepemimpinan, manajemen dan budaya maka akan semakin baik pula pelaksanaan praktek keperawatan di institusi tersebut. Upaya yang dapat dilakukan untuk terwujudnya pelaksanaan praktek keperawatan adalah dengan menciptakan budaya organisasi yang kondusif, adanya dukungan yang optimal dari pemimpin maupun manajemen dan tentunya upaya ini akan berdampak pada peningkatan kualitas asuhan yang akan diterima klien.

\section{Kendali Terhadap Beban Kerja}

Kondisi kerja yang beban kerja semakin meningkat di ruangan merupakan suatu kondisi yang dapat meningkatkan kesalahan dalam bekerja dan tentunya hal ini akan berdampak pada penurunan kualitas asuhan yang diberikan kepada klien (12). Kondisi ini tentunya diperlukan suatu kemampuan atau otoritas yang dimiliki oleh perawat dalam mengelola beban kerjanya dan kemampuan ini berdampak positif pada meningkatnya kualitas asuhan keperawatan yang diberikan oleh perawat $(5,11)$. Hal ini sesuai dengan temuan dalam penelitian ini yang menunjukkan ada pengaruh yang positif antara kendali terhadap beban kerja dengan 
pelaksanaan praktek keperawatan, artinya semakin tinggi kendali beban kerja yang dimiliki oleh perawat maka akan semakin tinggi pula kualitas pelaksanaan praktek keperawatannya.

\section{Kendali Terhadap Praktek}

Praktek keperawatan profesional merupakan suatu sistem yang memberi dukungan bagi perawat untuk dapat memiliki kendali terhadap lingkungan praktek dalam memberikan asuhan kepada klien yang akan berkontribusi pada peningkatan layanan pada klien maupun organisasi. Semakin baik kendali praktek yang dimiliki oleh perawat akan semakin baik pula pelaksanaan praktek keperawatannya (1). Perawat melalui otonomi yang dimilikinya dalam kendali terhadap praktek akan memperoleh keleluasaan dan bertanggung jawab atas pelaksanaan, keberhasilan atau kegagalan suatu pekerjaan, sehingga menimbulkan rasa diberdayakan (13). Selain itu bahwa manfaat dari otonomi yang dimiliki oleh perawat melalui kendali terhadap prakteknya adalah dapat meningkatkan partisipasi dalam pembuatan keputusan, meningkatkan ketrampilan klinik, memfasilitasi kerja tim multidisiplin yang lebih efektif dan tentunya akan berdampak pada peningkatkan kualitas asuhan keperawatan yang diberikan pada klien (14). Hal ini selaras dengan penemuan dalam penelitian ini yang menunjukan ada pengaruh yang positif dari kendali yang dimiliki oleh perawat terhadap prakteknya pada pelaksanaan praktek keperawatan. Kendali terhadap praktek dalam penelitian ini merupakan faktor yang paling besar pengaruhnya terhadap pelaksanaan praktek keperawatan, pelaksanaan praktek keperawatan akan bertambah 1,301 kali bila perawat memiliki kendali terhadap praktek setelah dikontrol subvariabel kendali terhadap beban kerja dan sumber yang memadai.

\section{Sumber Yang Memadai}

Ketersediaan sumber yang memadai sangat signifikan mempengaruhi kualitas asuhan keperawatan yang diberikan, artinya semakin baik sumber yang memadai akan semakin baik pula pelaksanaan praktek keperawatannya (1). Hal ini sesuai dengan temuan dalam penelitian ini yang menunjukkan ada pengaruhnya sumber yang memadai terhadap pelaksanaan praktek keperawatan. Tersedianya sarana dan prasarana secara optimal baik dari segi kuantitas maupun kualitasnya yang sesuai untuk melaksanakan tugas keperawatan, serta adanya kesempatan bagi perawat untuk mengembangkan profesinya melalui pendidikan keperawatan berkelanjutan disesuaikan dengan kompetensi tiap jenjang karir klinik yang ada di ruangan tersebut maka akan semakin mudah terwujudnya pelaksanaan praktek keperawatan secara profesional.

\section{Implikasi Terhadap Pelayanan Keperawatan}

Penelitian ini mempunyai dampak positif terhadap peningkatan mutu pelayanan asuhan keperawatan di rumah sakit. Penelitian ini diharapkan dapat dijadikan bahan untuk peningkatan pelayanan asuhan keperawatan. Kepemimpinan, manajemen, dan budaya memiliki hubungan dengan pelaksanaan praktek keperawatan sehingga dengan pengelolaan yang baik akan berdampak terhadap peningkatan kualitas asuhan yang diberikan kepada klien.

Hasil penelitian tentang kendali terhadap beban kerja dapat dijadikan dasar untuk meningkatkan kualitan pelayanan asuhan keperawatan. Diketahui bahwa peningkatan kendali terhadap beban kerja yang dimiliki oleh perawat akan menentukan peningkatan praktek keperawatan yang dilakukan oleh perawat sehingga sangatlah wajar jika pihak manajemen keperawatan rumah sakit perlu mengupayakan untuk memberikan kewenangan kepada perawat untuk mampu mengelola beban kerjanya secara penuh.

Kendali terhadap praktek merupakan dasar yang harus dimiliki oleh perawat untuk memberikan asuhan keperawatan yang optimal dan berkualitas kepada kliennya. Pada penelitian ini didapatkan hasil bahwa kendali terhadap praktek merupakan faktor yang paling berpengaruh terhadap pelaksanaan praktek keperawatan, untuk itu perlu dikembangkan suatu sistem atau kebijakan yang memungkinkan perawat lebih memiliki kendali terhadap prakteknya.

Pelaksanaan praktek keperawatan tidak terlepas dari adanya sumber yang memadai untuk terselenggaranya praktek tersebut. Pengembangan profesional yaitu kesempatan untuk mengikuti pelatihan, seminar, dan pendidikan berkelanjutan serta tersedianya peralatan keperawatan yang memadai sangat diperlukan untuk peningkatan perawat dalam kemampuan prakteknya. Pada penelitian ini didapatkan hasil bahwa sumber yang memadai memiliki hubungan dengan pelaksanaan praktek keperawatan, untuk itu perlu dikembangkan suatu sistem dan program pengembangan profesional yang terstruktur.

\section{Implikasi Terhadap Penelitian Keperawatan}

Lingkungan kerja perawat yang terdiri dari kepemimpinan, manajemen, dan budaya, kendali terhadap beban kerja, kendali terhadap praktek serta sumber yang memadai merupakan salah satu faktor yang diketahui berpengaruh terhadap praktek keperawatan, masih ada beberapa faktor yang lain seperti iklim organisasi, struktur organisasi, dan kepuasan klien yang juga diduga berpengaruh terhadap pelaksanaan praktek keperawatan. Sehingga sangat perlu dilakukan penelitian lanjutan tentang faktor lain yang diduga mempengaruhi pelaksanaan praktek keperawatan tersebut.

\section{KESIMPULAN}

Berdasarkan hasil analisis data dan pembahasan yang telah dilakukan, dapatlah ditegakkan beberapa kesimpulan sebagai berikut:

Lingkungan kerja perawat yaitu kepemimpinan, manajemen, dan budaya; kendali terhadap beban kerja; 
kendali terhadap praktek dan sumber-sumber yang memadai memiliki hubungan dengan pelaksanaan praktek keperawatan

Kendali terhadap beban kerja, kendali terhadap praktek dan sumber yang memadai merupakan faktor yang dapat menentukan pelaksanaan praktek keperawatan. Kendali terhadap praktek merupakan sub variabel yang paling besar menentukan persepsi pelaksanaan praktek keperawatan di Rumah Sakit Umum Dr. Saiful Anwar Malang.

\section{SARAN DAN REKOMENDASI}

1. Bagi Manajer Keperawatan dan Pimpinan RSU Dr. Saiful Anwar perlu dibuat suatu kebijakan di rumah sakit yang mengatur tentang kepemimpinan, manaje- men, dan budaya; kendali terhadap beban kerja; kendali terhadap praktek dan sumber yang memadai.

2. Bagi Profesi perlu disusun suatu pedoman lingkungan kerja perawat yang terdiri dari kepemimpinan, manajemen, dan budaya; kendali terhadap beban kerja; kendali terhadap praktek dan sumber yang memadai serta sosialisasi tentang sistem jenjang karir perawat dan program pendidikan berkelanjutan bagi perawat di rumah sakit.

3. Bagi Penelitian Lanjutan mengingat penelitian ini masih mengandung beberapa kelemahan, bagi peneliti yang akan melakukan penelitian tentang lingkungan kerja perawat, dan pelaksanaan praktek keperawatan, disarankan untuk menggunakan observasi (time motion study), studi komparatif, atau desain eksperimen.

\section{DAFTAR KEPUSTAKAAN}

1. Mark AB, Salyer J, \& Wan THT. Professional Nursing Practice: Impact on Organizational and Patient Outcomes. JONA Lippincot Williams\&Wilkins,Inc. 2003; 33,4

2. Aiken L, Clarke S, Sloane D, et al. Nurses' Reports on Hospital Care in Five Countries. Health Affair; May/Jun 2001; 20(3): 43-53.ABI/INFORM Global.

3. Kamil H. Hubungan Antara Iklim Kerja dengan Penerapan Proses Keperawatan di Ruang Rawat Inap RSU Dr. Zaenal Abidin Banda Aceh. [Tesis]. Jakarta: Program Pasca Sarjana FIK UI. Tidak di terbitkan. 2001

4. Netty E. Hubungan antara Karakteristik Perawat Pelaksana, Pemahaman Proses Keperawatan dan Supervise dengan Penerapan Proses Keperawatan di Ruang Rawat Inap RSABHK Jakarta. [Tesis]. Jakarta: Program Pasca Sarjana FIK Ul. Tidak di terbitkan. 2002

5. Brooks AB, Anderson AM. Nursing Work Life in Acute Care. Journal of Nursing Care Quality : Jul-Sep 2004; 19,3

6. Registered Nurses Association of British Columbia, Guidelines for a Quality PracticeEnvironment for Registered Nurses in British Columbia. 2005 http://www.findarticles.com [accessed 10 November 2005]

7. Lowe GS. Quality of Worklife Indicators for Nurses in Canada, Workshop report.Ottawa: Canadian Nurses's Association. 2002

8. McCusker J, Dendukuri N, Cardinal L, Laplante J, et al. Nursing Work Environment and Quality Care: Differences between Units at the Same Hospital. ABI? INFORM Global. International Journal of Health Care Quality Assurance 2004; 17 (6): 313.

9. Budge C, Carryer J, Wood S. Health Correlates of Autonomy, Control and Professional Relationships in the Nursing Work Environment.: Blackwell Publishing Ltd. Journal of Advanced Nursing 2003; 42(3): 260-268

10. Lovergen G, Rasmussen HB, \& Engstrom B. Working Conditions and the Possibility of Providing Good Care. Blackwell Science Ltd. Journal of Nursing Management 2002; 10: 201-209.

11. Gifford DB, Zammuto FR, Goodman AE, et al. The Relationship between Hospital Unit Culture and Nurses's Quality of Work Life. ABI/INFORM. Journal of Healthcare management ; Jan/Feb $2002 ; 47,1$

12. Seki Y \& Yamakazi Y. Effects of Working Conditions on Intravenous Medication Errors in a Japanese Hospital. Blackwell Published Ltd. Journal of Nursing management 2006; 14, 128-139.

13. Cavazos GF. Useful Ideas and Principles for the Implementation of Reinforcement Programs to Keep Milkers Motivated. 2003. http://www.nmconline.org/articles/milkermotv/pdf. [accessed 12 Februari 2006].

14. Currie V, Harvey G, West E, McKenna H, \& Keeney S. Relationship between Quality of Care, Staffing Levels, Skill Mix and Nurse Autonomy: Literature Review. Blackwell Publishing Ltd Journal of Advanced Nursing 2005; 51(1): 73-82. 